\title{
EL ACCESO A LA VIDEOGRABACIÓN DE AUDIENCIAS EN EL NUEVO PROCESO PENAL. COMENTARIO DE LA RESOLUCIÓN IVAI-REV/976/2013/II
}

\section{Carlos Martín GÓMEZ MARINERO*}

\section{INTRODUCCIÓN}

La legitimidad del Poder Judicial descansa, entre otras cuestiones, en las condiciones de independencia, inamovilidad, en los mecanismos de elección de los jueces, así como en la obligatoriedad de motivar los fallos. Además de los elementos citados, la transparencia dentro del proceso jurisdiccional constituye un elemento importante de la legitimación de las decisiones judiciales. ${ }^{1}$

En este sentido, la resolución del recurso IVAI-REV/976/2013/II cobra relevancia en la medida que el Instituto Veracruzano de Acceso a la Información analizó el reclamo de dos videograbaciones de audiencias públicas orales celebradas en el nuevo sistema de justicia penal acusatorio. Las videograbaciones, conforme al artículo 3o., fracción V, de la Ley de Transparencia y Acceso a la Información Pública para el Estado de Veracruz, son documentos en los que se registra el ejercicio de las facultades o la actividad del Poder Judicial del Estado de Veracruz.

Considerando lo anterior y los argumentos que sustentaron la negativa del Poder Judicial (infra, tema 4), el Instituto Veracruzano de Acceso a la Información reconoció que el acceso a la videograbación de audiencias ce-

\footnotetext{
* Maestro en derecho constitucional y administrativo por la Universidad Veracruzana, gomez_mom@hotmail.com.

Fecha de recepción: 27 de julio de 2015.

Fecha de dictamen: 22 de septiembre de 2015.

1 Así, se ha señalado que "la transparencia del trabajo cotidiano de los tribunales aparece actualmente como uno de los pilares de proceso de legitimación de las decisiones judiciales" (Tortolero, 2006: 345).
} 
lebradas dentro de un proceso penal no concluido constituye información reservada; sin embargo, estimó razonable permitir el acceso a las citadas audiencias a través de la elaboración de sendas versiones públicas.

Ahora bien, como lo hemos señalado, el propósito del presente estudio consiste en analizar las consideraciones que sustentaron la consabida determinación y sus implicaciones. Para ello examinaremos, en primer lugar, los alcances del derecho a la información, sus límites y su relación con el caso de las videograbaciones de audiencias judiciales; posteriormente, confrontaremos dichas cuestiones con el fallo emitido por el órgano garante.

\section{El CONTENIDO DEL DERECHO A LA INFORMACIÓN}

Conforme al artículo 19 de la Declaración Universal de los Derechos Humanos $^{2}$, el derecho a la información es la garantía fundamental de toda persona para atraerse información, informar y ser informada (Carpizo y Villanueva, 2002: 71). El derecho a la información es un derecho humano y, en consecuencia, parte del principio de interdependencia contenido en el artículo 1o. constitucional, esto es, establece relaciones recíprocas con otros derechos, de modo que la satisfacción de uno hace posible el disfrute de otros (P./J. 20/2014, 2014: 96).

De esta manera, el derecho de atraer información, informar y ser informado, se vincula — entre otros- con los siguientes: a) el acceso a los archivos, registros y documentos públicos; $b$ ) la libertad de expresión y de imprenta, y c) el derecho a enterarse de todas las noticias, sin exclusión de persona alguna, respectivamente (Carpizo y Villanueva, 2002: 72).

La Corte Interamericana de Derechos Humanos ha establecido que el derecho a "buscar" y "recibir informaciones" protege, a su vez, el derecho de toda persona a solicitar el acceso a la información bajo el control del Estado (Claude Reyes y otros vs. Chile, 2006: 43), es decir, el acceso a los archivos, registros y documentos públicos. ${ }^{3}$ Además, estableció que dicha información debe ser entregada sin necesidad de acreditar un interés

2 El derecho a la información se encuentra establecido, además, en los artículos 6o. de la Constitución Política de los Estados Unidos Mexicanos, 19 del Pacto Internacional de Derechos Civiles y Políticos, y 13 de la Convención Americana sobre Derechos Humanos.

3 En este orden de ideas, el artículo 4o. de la Ley General de Transparencia y Acceso a la Información Pública establece que el derecho humano de acceso a la información comprende, solicitar, investigar, difundir, buscar y recibir información. 
directo y que su entrega a una persona puede permitir, a su vez, que ésta circule en la sociedad. ${ }^{4}$

En este orden de ideas, el citado derecho no sólo contiene una dimensión individual sino una social o colectiva, como lo ha reconocido el Pleno de la Suprema Corte de Justicia de la Nación (P./J. 54/2008, 2008: 743), al establecer que el carácter individual posibilita el ejercicio de la libertad de expresión en un contexto de mayor diversidad de datos, voces y opiniones; mientras que el colectivo tiende a revelar el empleo instrumental de la información como mecanismo de control institucional.

Conforme al artículo 3o., fracciones IV y V, de la Ley de Transparencia y Acceso a la Información Pública para el Estado de Veracruz, el derecho de acceso a la información es la garantía que tiene toda persona para acceder a los documentos que los sujetos obligados generen, obtengan, transformen o conserven por cualquier título; se consideran como tales los expedientes, reportes, estudios, actas, resoluciones, oficios, acuerdos, directivas, directrices, circulares, contratos, convenios, instructivos, notas, memorandos, estadísticas o cualquier otro registro que documente el ejercicio de las facultades o la actividad de los sujetos obligados y sus servidores públicos.

Además, los artículos 3o., fracción IX, 40. y 7o. del mismo ordenamiento local establecen que la información es un bien público, que no se requiere acreditar interés legítimo para acceder a éste y que la información se encuentra sujeta al principio de máxima publicidad, con la única limitación de la información que tiene el carácter de restringido. ${ }^{5}$

\section{LOS LÍMITES AL DERECHO DE ACCESO A LA INFORMACIÓN}

Como se ha indicado, la única limitación para el acceso a la información pública lo constituye aquella que tiene el carácter de restringido (la. VII/2012

4 Se ha señalado que el derecho de acceso a la información, en sentido estricto, es "la prerrogativa de la persona para acceder a datos, registros y todo tipo de informaciones en poder de entidades públicas y empresas privadas que ejercen gasto público o cumplen funciones de autoridad, con las excepciones taxativas que establezca la ley en una sociedad democrática" (Villanueva, 2006: 68).

5 En un sentido similar, el artículo 4o. de la Ley General de Transparencia y Acceso a la Información Pública establece que "toda la información generada, obtenida, adquirida, transformada o en posesión de los sujetos obligados es pública y accesible a cualquier persona en los términos y condiciones que se establezcan en la presente Ley, en los tratados internacionales de los que el Estado mexicano sea parte, la ley federal, las leyes de las entidades federativas y la normatividad aplicable en sus respectivas competencias; sólo podrá ser clasificada excepcionalmente como reservada temporalmente por razones de interés público y seguridad nacional, en los términos dispuestos por esta ley". 
10a., 2012: 655), es decir, la que comprende las categorías de información reservada y confidencial.

Se trata — en ambos casos — de fines constitucionalmente válidos o legítimos para establecer limitaciones al derecho de acceso a la información, previstos en la Constitución Política de los Estados Unidos Mexicanos. ${ }^{6}$ Mediante el supuesto de información reservada se protege el interés público y a través de la información confidencial se tutela el derecho a la vida privada y los datos personales.

La información reservada es la que se encuentra temporalmente sujeta a algunas de las excepciones previstas en los artículos 12, 14, 15 y 16 de la Ley de Transparencia del Estado de Veracruz, ${ }^{7}$ mientras que la información confidencial tiene, a partir del 3 de octubre de 2012, una regulación específica en la Ley para la Tutela de los Datos Personales en el Estado de Veracruz.

Cada uno de los dos grupos que constituyen el límite del derecho a la información supone "una racionalidad diferente e implica una valoración distinta respecto de su aplicación a los casos concretos" (López-Ayllón y Posadas, 2007: 23).

Así, la clasificación de la información reservada se encuentra sujeta a la demostración de la prueba del daño, en la que los sujetos obligados deben justificar la hipótesis de excepción: que la liberación de la información pueda amenazar efectivamente el interés protegido por la norma y que el daño que pueda producirse con la liberación sea mayor al interés público de conocerla. ${ }^{8}$

Por otra parte, en cuanto a la protección de la privacidad opera la prueba de interés público. ${ }^{9}$ Respecto de este punto es importante destacar que

6 Así lo ha reconocido la Primera Sala de la Suprema Corte de Justicia de la Nación en dos criterios: 1a. VIII/2012 (10a.) y la. VII/2012 (10a.) relativos a la Ley Federal de Transparencia y Acceso a la Información Pública Gubernamental, aplicables —en lo que respecta a los límites del derecho de acceso a la información - tanto al caso de la Ley de Transparencia y Acceso a la Información Pública para el Estado de Veracruz, como a la Ley General de Transparencia y Acceso a la Información Pública.

7 Dichos preceptos son correlativos a los numerales 100 y 113 de la Ley General de Transparencia y Acceso a la Información Pública.

8 Véanse los artículos 14 de la Ley de Transparencia y Acceso a la Información Pública para el Estado de Veracruz y 104 de la Ley General de Transparencia y Acceso a la Información Pública y Protección de Datos Personales.

9 En relación con la protección de la privacidad se ha señalado que "esta protección suele ser más amplia e impone una restricción absoluta a la divulgación de los documentos que contienen esta información. Sin embargo, pueden existir circunstancias excepcionales en que el interés público justifique su divulgación. Estas circunstancias excepcionales 
la carga de la prueba para comprobar el interés público recae en quien solicita la información; es decir, el peticionario tiene que argumentar y probar que el interés público de conocer la actuación de las autoridades es preponderante por encima del interés de privacidad en relación con la información particular de que se trata (López-Ayllón y Posadas, 2007: 38).

\section{LA VIDEOGRABACIÓN DE AUDIENCIAS PÚBLICAS}

Un referente importante para el análisis del presente comentario es la sentencia BVerGE 103, 44 (2001) del Tribunal Constitucional Federal Alemán, ${ }^{10}$ que permite conocer los alcances del empleo de grabaciones en audiencias públicas y algunas razones útiles para explicar el derecho de acceso a éstas. La sentencia alemana señala que si bien las audiencias son una fuente de información, el legislador decide sobre su acceso público; esto es, el órgano legislativo debe reglamentar los procedimientos judiciales y atender a los aspectos constitucionales como el principio democrático y la protección de la personalidad (BVerGE 103, 44, 2001: 226).

En este sentido, el carácter público de los tribunales está garantizado en la ley, pero se ha previsto sólo para el caso de las salas de audiencia. La prohibición para las grabaciones y tomas fílmicas, con el objeto de ser transmitidas al público o de publicar su contenido, aplica a las publicaciones que llevan a cabo los medios de comunicación en forma indirecta (BVerGE 103, 44, 2001: 229). Es decir, lo que se restringe en sí es lo mediático ${ }^{11}$ de las citadas diligencias, sin que ello implique desvirtuar su carácter público, así debe entenderse el razonamiento del tribunal constitucional en el sentido de que el legislador "ha hecho uso por tanto de su derecho de disposición en forma tal que el acceso general se encuentra permitido sólo a aquellos que quieren seguir las audiencias judiciales en los espacios que se han previsto para tal efecto" (BVerGE 103, 44, 2001: 229).

suponen una difícil y compleja valoración de los intereses en juego. Algunos países han previsto en sus legislaciones los estándares que guían esta ponderación y que se conocen como la prueba de interés público" (López-Ayllón y Posadas, 2007: 23).

10 Otra resolución que se ocupa del tema es la STC 56/2014, del Tribunal Constitucional de España (Navarro, 2007: 14 y 15).

11 La doctrina procesalista distingue varios tipos de publicidad procesal: la publicidad para las partes y la publicidad general. Esta última puede ser inmediata, como ocurre con la asistencia directa de los ciudadanos a las audiencias públicas, o mediata, por un medio de comunicación presente en el juicio oral (Navarro, 2007: 4 y 5). 
El Tribunal Constitucional reconoció que sólo después de permitir el acceso general puede afectarse el ámbito de protección del derecho a la información, de modo que el derecho de acceso a una audiencia se encuentra sujeto a las reglas que al efecto establezca el legislador ordinario, restringiendo la modalidad a la presencia física del acto y vedando la grabación por parte de los medios masivos de comunicación. De esta manera, si bien a través del derecho de acceso se pretenden remover los obstáculos para la obtención de información de una fuente que cae dentro del ámbito de responsabilidad estatal (BVerGE 103, 44, 2001), en el caso de las audiencias públicas, el legislador puede establecer los términos y las modalidades del acceso a la fuente de información.

Atendiendo a un razonamiento análogo en México, el artículo 55 del Código Nacional de Procedimientos Penales reguló la utilización de las restricciones y el acceso a las audiencias. ${ }^{12}$ En ese mismo sentido, el artículo 136 del Código de Procedimientos Penales del Estado de Veracruz establece que la grabación o reproducción de imágenes o sonidos se considera como parte de las actuaciones y los registros, por lo que se conservarán en resguardo del Poder Judicial.

Con base en lo anterior, es válido cuestionarnos si el derecho de acceso a la información en el caso del reclamo de videograbaciones se satisface únicamente al acudir de manera presencial a una audiencia pública o si existe la posibilidad de conocer el desarrollo de una audiencia a través de otro medio indirecto que permita imponerse del contenido de ésta, respetando las reglas que limitan su publicidad mediata o mediática.

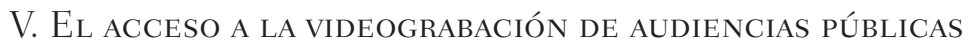 CONFORME A LOS ARgumentos del InSTITUto VERACRUZANo DE ACCESO A LA INFORMACión}

La materia del recurso IVAI-REV/976/2013/II consistió en el análisis de los argumentos que sustentaron la negativa del Poder Judicial para proporcionar las videograbaciones de dos audiencias públicas (la de control de detención y la de vinculación a proceso) celebradas dentro de un proceso penal.

En este orden de ideas, el Instituto Veracruzano de Acceso a la Información se abocó a analizar los motivos de negativa aducidos por el Poder

12 Así, de conformidad con el precepto citado, los periodistas o los medios de comunicación acreditados, deben informar de su presencia — en las audiencias públicas - al órgano jurisdiccional con el objeto de ubicarlos en un lugar adecuado para tal fin y deben abstenerse de grabar y transmitir por cualquier medio la citada diligencia. 
Judicial que fueron sustancialmente dos: a) que no es posible expedir al público las copias requeridas en atención al principio de presunción de inocencia, y b) que si bien las audiencias son públicas, una vez desahogadas forman parte de actuaciones judiciales que únicamente son asequibles a las partes, máxime que éstas forman parte de procesos penales no concluidos.

1. Argumento del respeto al principio de presunción de inocencia

El argumento relativo al respeto de la presunción de inocencia de los implicados en el proceso penal como motivo de impedimento para negar la entrega de la información fue desestimado por el órgano garante; en primer lugar, porque el Poder Judicial omitió indicar las razones por las que a su consideración se afectaba dicho principio y, en segundo lugar, porque con "la asistencia del público en general a las audiencias en los juicios orales, no se advierte razón válida para suponer que la publicidad posterior pueda traer aparejada un daño o perjuicio (al citado principio)" (IVAI-REV/976/2013/II, 2014: 13).

El órgano garante no distinguió entre lo mediático y lo público; sin embargo, tal y como hemos señalado con antelación, la restricción de videograbaciones a las audiencias públicas tiene que ver, precisamente, con la prohibición de filmar el desarrollo de las audiencias; dicha restricción considera diversos intereses como la protección de la personalidad, el debido proceso legal y de la búsqueda de la verdad y de la justicia (BVerGE 103, 44, 2001: 232).

2. Argumento relacionado con que si bien las audiencias son públicas, forman parte de actuaciones judiciales únicamente asequibles a las partes, máxime que formaban parte de procesos penales no concluidos

El Instituto Veracruzano de Acceso a la Información estimó que el Poder Judicial incumplió con el deber contenido en el artículo 14 de la Ley de Transparencia del Estado, en el sentido de que la autoridad —al fundar y motivar la clasificación de la información - debe cumplir con los siguientes requisitos: a) que corresponda legítimamente en alguna de las hipótesis de excepción prevista en la ley; $b$ ) que su liberación pueda amenazar efectivamente el interés protegido por la ley, y c) que el daño que 
pueda producirse con su liberación sea mayor que el interés público de conocerla. ${ }^{13}$

El Instituto de transparencia estimó que el Poder Judicial incumplió con la observancia del precepto antes referido porque omitió justificar la prueba de daño. Esto es, los elementos objetivos que permitiesen determinar si la difusión de la información causaría un daño presente, probable y específico a los intereses jurídicos tutelados por el artículo 12, fracción IV, de la Ley de Transparencia. ${ }^{14}$

Dicha argumentación se enfocó en justificar, por un lado, que la información reclamada si bien formaba parte de un proceso penal no concluido, tal circunstancia per se no acreditaba un daño a los intereses que tutela la categoría de información reservada y, por el contrario, la ponderación con el principio de publicidad debía dar como resultado la entrega de la información. Máxime que el hecho de tener acceso a las audiencias de un juicio oral no implica de ningún modo que se pueda tener conocimiento de alguna estrategia procesal, toda vez que las cuestiones debatidas en una audiencia deberán ser resueltas en ella, de conformidad con el artículo 126 del Código de Procedimientos Penales para el Estado de Veracruz. ${ }^{15}$

Asimismo, el órgano de transparencia local advirtió un verdadero conflicto de principios, no en la posibilidad de acceder a las videograbaciones o a los alcances del derecho de acceso a la información, sino en "la protección de los datos personales y la intimidad de las personas" (IVAIREV/976/2013/II, 2014: 14) ${ }^{16}$ dentro de las videograbaciones.

13 Para estudiar este argumento se debe partir de la premisa prevista en el artículo 12, fracción IV, de la Ley de Transparencia y Acceso a la Información Pública para el Estado de Veracruz, dicho precepto contempla como información reservada "las actuaciones y las resoluciones relativas a procedimientos judiciales o administrativos, cuando aún no hayan causado estado", habida cuenta que el Poder Judicial del estado adujo esta circunstancia respecto de las videograbaciones reclamadas. Esta hipótesis también se encuentra establecida en el artículo 1 13, fracciones X y XI, de la Ley General de Transparencia y Acceso a la Información Pública.

14 En este sentido, el órgano garante abundó en lo que respecta a la publicidad de la audiencia en el proceso penal, razonando que ésta lleva como intención el escrutinio público "que se convierte prácticamente en una medida de control de la sociedad sobre el quehacer del juzgador en materia penal, para garantizar incluso al acusado, la legalidad del proceso" (IVAI-REV/976/2013/II, 2014: 8). En relación con el principio de publicidad, la resolución en estudio se apoyó en la ejecutoria que originó la tesis 1a./J. 43/2013 (10a.).

15 Este precepto es correlativo al artículo 52 del Código Nacional de Procedimientos Penales.

16 Este mismo razonamiento se ha justificado cuando se señala que "las videograbaciones realizadas por particulares implican que la información generada en el órgano jurisdic- 
Por esta razón, el órgano garante estimó razonable ordenar al sujeto obligado que permitiera el acceso a la información bajo cualquiera de las siguientes modalidades: a) la proyección de las videograbaciones dentro de las oficinas de la Unidad de Acceso a la Información del Poder Judicial, cumpliendo con las reglas que en su momento observaron las personas que presenciaron las audiencias, y/o b) la elaboración de una versión estenográfica de las audiencias, con la eliminación de los datos personales que pudieran contener (IVAI-REV/976/2013/II, 2014: 14).

\section{Implicaciones DE LA RESOLUCión IVAI-REV/976/2013/II}

La resolución del recurso IVAI-REV-976-2013-II implicó reconocer que si bien el acceso a la videograbación de las audiencias dentro de un proceso penal no concluido puede estimarse como información reservada, ello es insuficiente para tener por acreditada la prueba del daño de manera absoluta. Como se puede advertir, el Instituto Veracruzano de Acceso a la Información abordó la problemática planteada desde el enfoque de la información reservada, es decir, la valoración en el caso concreto implicó el análisis de la prueba del daño por encima del estudio entre el interés de la privacidad y el interés público.

Además de las posibilidades desde los enfoques de la información reservada y confidencial, estimamos que el órgano garante debió plantear la posibilidad de examinar la aparente contradicción en los alcances del derecho a la información y el acceso a las videograbaciones de audiencias públicas. Con este análisis se destacaría, por una parte, las implicaciones de la circulación de la información en la sociedad y, por otro lado, identificar las reglas específicas que limitan el empleo de videograbaciones en dichas actuaciones judiciales.

Consideramos que para abordar y esclarecer la relación antes mencionada, el órgano garante debió partir — como ocurre en esta clase de casos- de la hipótesis siguiente: ¿el acceso corresponde al legítimo ejercicio del derecho a obtener y difundir información o por el contrario, debe encuadrarse dentro del derecho a un proceso público como garantía procesal de la tutela judicial efectiva? ${ }^{17}$

cional sale del mismo, imposibilitando al juez la rectoría del uso y destino de la misma... por tanto, no deben ser autorizadas" (Soto, 2011: 181).

17 Véase al respecto Navarro, 2007: 3. 
Un planteamiento de esta naturaleza, además del análisis de la prueba del daño y del interés público, permitiría, en primer lugar, sentar la base de una clara diferenciación entre las restricciones a la información pública a través de las categorías de información reservada y/o confidencial, y la regulación (en el ámbito de la tutela judicial efectiva) por parte del legislador a una fuente de acceso público. En este orden de ideas, estimamos que se soslayaron los razonamientos de la sentencia alemana BVerGE 103, 44, al reconocerse en ésta que el carácter público de las audiencias no implica la transmisión o publicación directa de su contenido.

A pesar de lo anterior, la argumentación planteada en la resolución del Instituto veracruzano es de significativa importancia, porque el estudio desde la perspectiva de la información reservada permitió advertir que la prueba del daño no restringe de manera absoluta el acceso a la información. Dicha prueba únicamente justificó la negativa de la entrega de las videograbaciones reclamadas, sin embargo, ello no se extiende a su acceso a través de otros medios, respetando el interés público protegido por la norma.

La resolución del órgano garante constituye un remedio creativo en el caso analizado en la medida que armonizó el principio de máxima divulgación (que opera en materia de transparencia) y el principio de publicidad (que rige en el nuevo sistema penal). La resolución no deja de reconocer la imposibilidad de entregar las videograbaciones, lo que se traduce en un verdadero ejercicio de proporcionalidad, que si bien en la actualidad se encuentra contemplado expresamente en el artículo 104, fracción III, de la Ley General de Transparencia y Acceso a la Información Pública — como uno de los parámetros para justificar la prueba del daño-, no así en la vigente Ley de Transparencia del Estado de Veracruz.

\section{Conclusión}

Si bien la transparencia de las actuaciones judiciales constituye un elemento importante de la legitimación de las decisiones judiciales, ésta no se ve alterada con la restricción o limitación de la difusión de videograbaciones de audiencias públicas. Se debe considerar que sí existe un acceso a la fuente de información; no obstante, se realiza a través de la asistencia física o de otros medios de publicidad indirecta, como las versiones estenográficas.

En el caso alemán, para abordar la problemática, el Tribunal Constitucional consideró el interés tutelado en la norma local (información reservada) confrontado con los principios de máxima divulgación y publicidad procesal penal, más allá de la valoración de los derechos de las partes invo- 
lucradas, la protección de la personalidad de éstas y la no perturbación de la actividad judicial. La sentencia consideró que la difusión de tomas audiovisuales pudiera generar, entre otros efectos, "la vergüenza que produce la presentación en público de la conducta ante el tribunal, o debido a los recuerdos negativos del proceso que quedan en la memoria del público, se puede dificultar la posterior resocialización” (BVerGE 103, 44, 2001: 232).

Por su parte, el órgano garante mexicano, en uno de los párrafos de la resolución, indicó que el verdadero conflicto de principios no se encontraba en fijar los límites del derecho de acceso a la información ni en la posibilidad de acceder a las videograbaciones, sino que éstas contienen datos personales y, en esta medida, debía ordenarse la elaboración de la versión pública de la información. La técnica y los argumentos empleados por el Instituto veracruzano se encaminaron en desvirtuar las consideraciones relativas a la información reservada. La solución se direccionó en la elaboración de una versión pública de la información, con lo que limitó la publicidad mediata o mediática de las audiencias y se aproximó a los fines que persigue el derecho de regulación de la fuente de información por parte del legislador ordinario, conforme a la sentencia del tribunal alemán BVerGE 103, 44 (2001).

Como lo hemos mencionado, el tema abordado por el Instituto Veracruzano de Acceso a la Información involucró indirectamente las razones por las que el acceso a la información de una audiencia pública no sólo se satisface con el hecho de acudir físicamente a la citada diligencia sino de otras formas de publicidad inmediata.

Finalmente, debemos destacar la relevancia de la resolución en la medida que aplica un examen de proporcionalidad sin que el mismo se encuentre previsto expresamente en la Ley de Transparencia del Estado vigente, a diferencia de la Ley General de Transparencia, cuya determinación constituye uno de los primeros esfuerzos en armonizar los principios que rigen el derecho a la información y el nuevo sistema de justicia penal acusatorio.

\section{BibLiografía}

Carpizo, Jorge y Villanueva, Ernesto, 2007, "El derecho a la información propuestas de algunos elementos para su regulación en México", en VALadés, Diego y GutiérRez, Rodrigo (coords.), Derechos humanos. Memoria del IV Congreso Nacional de Derecho Constitucional, México, UNAM, Instituto de Investigaciones Jurídicas. 
López-Ayllón, Sergio y Posadas, Alejandro, 2007, "Las pruebas de daño e interés público en materia de acceso a la información. Una perspectiva comparada”, Derecho Comparado de la Información, México, núm. 9.

Navarro Marchante, Vicente J., 2007, "Las imágenes de los juicios: aproximación a la realidad en España”, Indret. Revista para el Análisis del Derecho, Barcelona, núm. 3, julio.

100 Soto Morales, Carlos Alfredo, 2011, "Transparencia judicial", Revista del Instituto de la Judicatura Federal, México, núm. 32.

Tortolero Cervantes, Francisco., 2006, "El secreto de las deliberaciones judiciales a debate", Revista de la Facultad de Derecho de México, México, - núm. 245.

Villanueva, Ernesto, 2006, Derecho de la información, México, Miguel Ángel Porrúa. 